\title{
LA PALABRA PERSUASIVA. CENTROS DE INTERÉS DE LA RETÓRICA DE ARISTÓTELES
}

\author{
Quintín Racionero
}

RESUMEN. El autor hace un balance de las novedades incorporadas, en el ámbito de las investigaciones aristotélicas, por su traducción al español de la Retórica de ARISTótelES. Para el autor, la suya no fue sólo una traducción sino, sobre todo, un comentario sistemático que intenta en primer lugar en la Introducción del libro evaluar el estado de la investigación contemporánea en torno a la Retórica, proponiendo una interpretación sintética de alcance general; y en segundo lugar, en las notas a pie de página, 1.580 notas, para decirlo con exactitud, fijar y discutir puntualmente los problemas de crítica textual, análisis histórico y examen filosófico que el texto de ARISTÓTELES plantea y para los que aquella investigación contemporánea ofrece nuevas perspectivas y enfoques. En armonía con aquello, el autor efectúa el balance objeto de este artículo en tres bloques: el de la crítica textual, el del análisis histórico y del examen filosófico.

Palabras clave: Aristóteles, retórica, dialéctica.

ABSTRACT. The author takes stock of the latest contributions, in the scope of research into ARISTOTLE, resulting from his translation into Spanish of "Rhetoric". In the author's opinion, his work is not only a translation but, above all, a systematic commentary which firstly -in the introduction to the bookseeks to assess the situation of contemporary research into "Rhetoric", putting forward a synthetic interpretation of general scope and secondly- in the footnotes: 1.580 footnotes, to be precise- seeks to establish and discuss in a accurate way the problems associated to the textual critique, the historical analysis and the philosophical examination which ARISTOTLE'S text raises and for which this contemporary research offers new perspectives and approaches. In the same way, the author's approach is carried out in three sections: textual critique, historical analysis and philosophical examination.

Keywords: Arstoteles, rethoric, dialectic. 


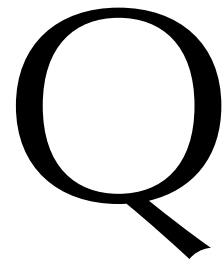

uisiera, ante todo, agradecer muy vivamente al Departamento de Filosofía del Derecho y a su director, don Manuel ATIENZA, esta invitación a participar en un curso de postgrado, cuyo título, «Clásicos de la Argumentación», así como el de la misma ponencia que se me pide que desarrolle, «La Retórica de Aristóteles», parece que me obligan a hacer balance de los resultados que obtuve, hace ya más de una década, con motivo de mi publicación de una nueva traducción al español de la Retórica de ARISTÓTELES. Esta traducción incorporó en su día, y creo que aún sigue incorporando, algunas novedades en el ámbito de las investigaciones aristotélicas, que han sido objeto de atención - a veces elogiosa, a veces críticamente- de bastantes estudiosos. Pues bien, es a esas novedades (a su análisis, pero, sobre todo, al sometimiento al juicio crítico de los componentes de este Seminario) a lo que me propongo dedicar esta exposición.

Por razones que fundamentalmente se refieren al fenómeno, ya superado ahora, pero constatable hasta hace bien poco, del descrédito de la retórica, entendida como técnica de la argumentación y como preceptiva de los discursos, lo cierto es que la obra de ARISTÓTELES que lleva este nombre es la única de las que componen el Corpus que no había vuelto a ser comentada íntegramente en el curso de este siglo. Si se exceptúa el trabajo de W. H. GRIMALDI Aristotle's Rhetoric. A Comentary, que, por el fallecimiento de su autor, sólo alcanza a los libros I y II, los últimos comentarios disponibles y también los únicos hechos con criterios científicos eran, efectivamente, el de L. SPENGEL, que acompañaba a su edición de 1867; y el muy meritorio de E. M. COPE, que, a la muerte de éste, completó y editó J. E. SANDYs en 1877. Esto quiere decir que la Retórica no se había beneficiado todavía o, al menos, no más que parcialmente, de una revisión exhaustiva que incorporase, para la totalidad del texto, la investigación aristotélica de los últimos cien años. Y si se considera, como todos saben, que ha sido precisamente este tiempo el que ha conocido la más ingente y decidida renovación de los estudios sobre ARISTÓTELES, y ello además en una forma que ha tenido como objetivo su desvinculación de las tradiciones interpretativas escolásticas y su plena restauración histórica, se comprende entonces que tal carencia constituyese una enorme laguna, sobre la que mi trabajo ha pretendido, si no otra cosa, al menos echar las bases de un futuro puente.

Y en efecto: mi trabajo no es sólo, o no tanto, una traducción, por más que yo haya asumido esta tarea en la forma instrumental, para lectores de habla española, más decorosa que me ha sido posible; mi trabajo es, sobre todo, un comentario sistemático que intenta, en primer lugar, en la Introducción del libro hacer balance del estado de la investigación contemporánea en torno a la Retórica, proponiendo una interpretación sintética de alcance general; y en segundo lugar, en las notas a pie de página: 1.580 notas, para decirlo con exactitud, fijar y discutir puntualmente los problemas de crítica textual, análisis histórico y examen filosófico que el texto de ARISTÓTELES plantea y para los que aquella investigación contemporánea ofrece nuevas perspectivas y enfoques.

\section{II}

Por lo que atañe a los problemas de crítica textual, primeros a los que querría referirme, poco es, desde luego, lo que me ha cabido añadir a la breve, pero monu- 
mental obra de R. KASSEL, 1971: Der Text der aristotelischen Rhetorik, Berlín-Nueva York, que ha estudiado con particular minucia los códices griegos conocidos, así como los escolios y las traducciones latinas de la Retórica, de un modo que supera ampliamente las conclusiones muy acreditadas y seguidas casi sin discusión por los editores posteriores, pero en realidad muy inseguras y sostenidas sobre un material muy escaso del estudio de RoEmeR, «Zur Kritik der Rhetorik des Aristoteles», publicado en 1884 y base de su edición teubneriana de 1898. Cierto es que KASSEL no ha podido atender con igual pericia, por no ser de su competencia profesional, el estudio de las traducciones árabes, sobre las que yo tampoco podría pronunciarme y sobre las que sólo cabe decir que esperan a un paciente arabista que pueda analizarlas. Cierto es también que sus criterios metodológicos se han mantenido en la esfera, a mi juicio demasiado conservadora, de la filiación de los "errores" de los códices, lo que sólo puede sostenerse sobre la base de una confianza en la posibilidad de reconstruir un arquetipo único de la Retórica, que la propia fragmentación de la tradición manuscrita hace discutible a cada paso. La consecuencia de ello es que su nueva edición de la Retórica, publicada en 1976, no ha logrado, a lo que yo juzgo, sacar todo el partido que sus investigaciones textuales hacían esperar. Pero si con esto quiero decir que mi trabajo no siempre ha estado de acuerdo con algunas de las hipótesis críticas ni, desde luego, con todas las lecturas particulares fijadas por KASSEL, en cambio, por lo que se refiere a la historia de la transmisión y a la génesis de los diversos códices, me parece que el stemma obtenido por él tiene visos de ser definitivo, al menos si nuevos descubrimientos textuales, hoy improbables, no proporcionan elementos distintos a los de la tradición manuscrita que conocemos.

El stemma de KASSEL se apoya sobre la base de una reconstrucción de las diversas procedencias de los códices deteriores, que ROEMER había utilizado en bloque, suponiéndolos una familia única de manuscritos ${ }^{*}$ ) dependientes de un original griego ( (), del que también dependerían, en rama separada, las traducciones latinas. De seguirse esta opinión de ROEMER, todas las heterogeneidades de los deteriores deberían interpretarse entonces como errores de copia, errores que habrían ido reproduciendo e incrementando los sucesivos copistas con el paso del tiempo. Consecuentemente, el criterio de buen códice debía recaer en exclusividad, de una parte, sobre el que BEKKER puso bajo la sigla A', el n. ${ }^{\circ} 1.741$ de la Biblioteca de París, de la segunda mitad del siglo $\mathrm{X}$, que es el más antiguo de los que conservamos; $\mathrm{y}$, de otra parte, sobre el texto conjeturable de ese original griego (al que, según sus conclusiones, seguían conjuntamente los deteriores y las traducciones latinas. Y como el códice A` presenta muchas enmiendas así interlineales como marginales y a veces de la misma mano, a veces de mano distinta, que hasta cierto punto pueden ponerse en relación con ese texto conjetural al que acabo de referirme, de ambas fuentes ROEMER creyó que se podía reconstruir un texto común $(\exists)$ que, a su juicio, debía considerarse como copia de un arquetipo único $(\forall)$.

El estudio de KASSEL demuestra que estas hipótesis de ROEMER eran excesivamente simplistas e imposibles de sostener. El códice parisino A` comporta ciertamente una rama de la tradición manuscrita y debemos suponerlo copia de un original griego único, que sería el que ROEMER identifica con el arquetipo $\forall$. En cambio, en primer lugar, las enmiendas de $\mathrm{A}^{`}$ no pueden explicarse por correcciones de lecturas posteriores, sino que proceden de la consideración de un segundo manuscrito, que KASSEL 
coloca bajo la sigla ) y que también debe ser copia de un original griego distinto del anterior, al que habría que identificar, con carácter autónomo, con el llamado $\exists$ por Roemer. Tenemos así que la tradición manuscrita de la Retórica no puede reducirse a una fuente o a un arquetipo único, sino que remite, al menos, a dos originales griegos diferentes. Pero además, en segundo lugar, las traducciones latinas tampoco pueden relacionarse sin más con el conjunto de los deteriores, sino que forman una familia aparte, procedente de un tercer original griego (el que hemos referido como () que mezcla los dos anteriores: de las páginas 1354a a 1369 y de 1386b hasta el fin, tal original sigue de cerca a $\forall$; y de $1369 \mathrm{~b}$ a $1386 \mathrm{a}$ se inspira en $\exists$. Esto permite comprender las afinidades, notadas por RoEmER, entre el texto conjeturable de las traducciones latinas y la copia corregida del códice A', sin necesidad de suponer a aquéllas como dependientes de éste; y, por otra parte, la factura de tal texto conjeturable, así descrito, es la que parece desprenderse de las citas de Dionisio de Halicarnaso y la que se puede reconocer en el cód. Marcianus, 214, del siglo XIII, que fue estudiado por HORNA bajo la sigla $\mathrm{H}$ y cuya importancia queda de este modo verificada.

La importancia de estos datos, que complican el stemma de RoEMER y que (a pesar de la confianza mantenida por el propio KASSEL) convierten en muy improbable cualquier pretensión filológica de llegar a un arquetipo único, no se ciñe, de todos modos, a fijar con más rigor la historia de la recepción manuscrita de la Retórica. Tal importancia estriba más bien en que hace posible una discriminación detallada de la diferente génesis de los llamados deteriores, acreditando su distinto valor y potenciando consecuentemente algunas de sus lecturas. De la versión corregida de A` depende sin duda el cód. de Dresde DA 4, de la primera mitad del siglo XV, que sirve de matriz a otros varios, únicos para los que aún es válida la hipótesis de ROEMER sobre el origen común de los deteriores a partir de un presunto manuscrito (. En cambio, los dos códices iluminados de TüBINGEN (Tu I y II), así como los Laurent, 60.10 (La) y Laurent. Convent, 47 (Co) y el propio Monac., 313, estudiado por ROEMER, nos permiten reconstruir el texto conjetural del códice identificado por KASSEL como ) y al que, según he dicho, debemos suponer copia de $\exists$. Por su parte, este original griego $(\exists)$ nos lo podemos representar hoy con la mayor certeza a partir del manuscrito Cantabrigensis, 1298, de los siglos XII-XIII, que KASSEL ha puesto bajo la sigla F y que, por esta razón, debe considerarse un texto digno del mismo crédito que $\mathbf{A}^{`}$ y copia, como éste, de un original griego antiguo.

El cód. Cantabrigensis tiene una descendencia particularmente rica: de él depende, en efecto, de una parte, la familia de manuscritos que se relacionan con el Vaticanus Palatinus, 23, de la segunda mitad del siglo XIII, manuscrito éste bien conocido y estudiado desde BEKKER, que lo puso bajo la sigla $\mathbf{Z}$ y cuyas variantes deben ser atendidas, por tanto, con el interés que merecen; $y$, de otra parte, en rama separada, la familia en este caso enorme de manuscritos que derivan de la versión corregida del Cantabrigensis, que KASSEL llama $\mathbf{F}^{2}$ y cuyas enmiendas, aunque sin justificaciones explícitas, supone también muy antiguas. Sería inútil, naturalmente, que yo intentase recomponer aquí, siquiera fuese en síntesis, las ramas, líneas de filiación y manuscritos concretos que pertenecen o se hallan vinculados con esta familia de códices. En cambio, sí querría dedicar unos muy breves comentarios al más importante de ellos, que había sido desatendido hasta el profundo análisis de KASSEL y cuya colación sistemática constituye seguramente el único punto de crítica textual que yo me atreve- 
ría a destacar en mi edición de la Retórica. Me refiero al cód. Matritensis, 4684, de principios del siglo XIV, que se conserva en la Biblioteca Nacional de España.

La atención a este códice se halla, desde luego, llena de consecuencias. Ante todo, según ha mostrado KASSEL, por la propia riqueza de sus derivaciones. El texto y los excerpta de este códice Matritensis dan vida, en efecto, a la mayor familia de manuscritos conocidos: el Vatic., 265, que debe ponerse en relación con el Ambros., L 76 y con el Vatic., 1580 (que parece asimismo depender de Z); el Laurent., 60.18, al que siguen el Magliabechanus, II.10.59 de Florencia y el Matrit., 4687, este último copiado, a su vez, por el Angelicanus de Roma y el célebre Alexandrinus; y, finalmente, el Vatic., 2384 y su descendencia: el Vatic. Palatinus, 160, el Vatic., 1002, el Paris., 2042 y el Marcianus, 200, que figura con la sigla $\mathbf{Q}$ en BEKKER. La propia edición príncipe, la Aldina de 1508, se relaciona con este grupo de manuscritos, si bien su recensio presupone igualmente el Paris., 2038, llamado D por GAISFORD, y, con toda seguridad, otro manuscrito diferente, hoy perdido para nosotros. Ahora bien, la magnitud de esta familia de códices, insisto: la mayor conocida, no es la única causa de la importancia del Matritensis, 4684. A ello hay que añadir que, siendo éste el primer manuscrito que incorpora en escritura sistemática las enmiendas de $\mathbf{F}^{2}$, resulta así que estamos obligados a ver en él el ejemplo más antiguo, no fragmentario, de lo que debería calificarse como una segunda versión de F. Éste es el punto en el que me aparto de KASSEL y en el que creo que pueden hacerse efectivas las críticas de conservadurismo metodológico a que antes he hecho referencia. Pues como, a decir verdad, nada podemos decir sobre la data de las correcciones que presenta el Cantabr., a propósito de las cuales es meramente gratuita tanto la suposición de su antigüedad como la interpretación que hace de ellas enmiendas de "errores", todo lo que puede afirmarse y lo único que permanece como un hecho es que el códice madrileño ofrece una lectura autónoma coincidente en general con las enmiendas de $\mathbf{F}^{2}$, pero objetivada de un modo unitario, así orgánica como estructuralmente del mismo original griego $\exists$ (o de otro muy similar) al que también copia $\mathbf{F}$. Ello convierte, en fin, al Matritensis en un testimonio inapreciable para fijar la tradición manuscrita del segundo de los arquetipos y aumenta su importancia hasta situarlo en el mismo nivel de trascendencia que el Cantabr. para la reconstrucción de la Retórica de ARISTÓTELES.

Por lo demás, en lo que se refiere a los detalles concretos de tal reconstrucción, los criterios y argumentaciones que acabo de señalar proporcionan algunas bases firmes que, si no modifican sustantivamente, como es natural, el texto de ARISTÓTELES, permiten llevar a cabo una recensio más segura, sobre la que he procurado guiar, en todo caso, las decisiones textuales singulares de mi edición. Me limitaré aquí a presentar tres rápidos ejemplos, que recogen ordenadamente los tres supuestos fundamentales en que se resume cuanto llevo dicho. En primer lugar, y desde luego, es obvio que el mejor conocimiento de la tradición manuscrita limita drásticamente los afanes correccionistas de todos aquellos editores que son y éstos son muchos, en el caso de ARISTÓTELES, demasiado proclives a las conjeturas. Cuando las familias de códices coinciden, habida cuenta de la fragmentariedad de éstas y de su más que verosímil dependencia de originales griegos distintos, no debe admitirse corrección alguna del texto, pues la coincidencia asegura en este caso la certeza de la lección. Esto es lo que ocurre, por ejemplo, en I, 1, 1354a 8, donde tanto $\mathbf{A}^{`}$ como $\mathbf{F}$ y sus derivados (también el Matrit.), así como $\mathbf{H}$, que representa a las traducciones latinas, ofrecen bodopoieîn. No hay nin- 
guna razón para seguir admitiendo la corrección de BYWATER bodô $i$ poieîn, a la que han dado su asentimiento la gran mayoría de los editores, entre ellos el propio KASSEL. $\mathrm{Y}$, en efecto, una consideración algo más atenta demuestra que el happax aquí empleado por ARISTÓTELES se halla bien atestiguado en textos como Met. A, 3, 984a18 y Rhet., III, 14, 1414b21, que fija hodopoîesis; y la misma lectura, procedente de una segura tradición aristotélica, se observa asimismo en el fragmento de Zenón I, 72 (Arnim), que dice: «téchne éstin héxis bodopoietiké».

En segundo lugar, los códices tenidos por deteriores, pero de los que hoy sabemos que representan lecturas autónomas de verosímiles originales griegos diversificados (en concreto $\mathbf{H}, \mathbf{F}$ y los dos derivados, en ramas separadas, de este último: $\mathbf{Z}$ y el Matrit.) tienen que atenderse con el mayor escrúpulo, sin acceder a la conservadora teoría de los "errores" de copia; más aún: incluso deben preferirse a A', cuando, coincidiendo ellos entre sí, difieren de este último. Un ejemplo, entre otros varios, interesante por cuanto precisa en un sentido particular el texto aristotélico, lo ofrece II, 26, 1403a25, en donde se lee: állo tèn kataskeuastikén. Esta frase falta en A; por lo que casi todos los editores la atetizan, y también KASSEL. La frase está asimismo ausente de las traducciones latinas, pero este dato es aquí irrelevante, puesto que se halla localizada en esa parte de la Retórica en que el manuscrito griego conjetural, que las traducciones siguen, reproduce, según he explicado antes, al arquetipo de A`. En cambio, la frase está en todos los deteriores sin excepción que dependen de $\mathbf{F}, \mathbf{Z}$ y el Matrit. Y como debemos suponer que estos códices siguen un original griego auténtico el que hemos identificado con $\exists$, cuyas variantes es gratuito considerarlas como "errores" de copia, la conclusión sólo puede ser que la frase en cuestión es verdaderamente aristotélica y que no debe borrarse. Si leemos ahora el texto completo, lo que el filósofo quiere decir, entonces, no es tanto que «las refutaciones son una especie de los entimemas», sino que «no son una especie de entimemas distinta de los ya establecidos», lo que precisa con mayor rigor el pensamiento de ARISTÓTELES.

Por último, el tercer caso a que quiero referirme es el que se produce cuando las familias de códices difieren entre sí en una lectura concreta, sin que se den asociaciones significativas ni criterio alguno, salvo el de "buen códice", que justifique la preferencia de una sobre otra. El ejemplo más contundente de esta posibilidad es el que ofrece III, 10, 1410b36, que KASSEL ni siquiera menciona. A y todos sus deteriores escriben aquí enárgeia, es decir, 'claridad', 'nitided', lo que es conforme con la doctrina de ARISTÓTELES sobre la metáfora. En cambio, las traducciones latinas y el Matrit. escriben enérgeia, que, además de ser un término aristotélico por excelencia, tiene a su favor el comentario del escoliasta, que lo fija sin ninguna duda: «tinà tôn antigráphon échousin energếas» $\left(\sum\right)$. Este último testimonio ha llevado a los editores sin excepción a preferir enérgeia, en vez de enárgeia. Sin embargo, mi opinión es que en estos casos debemos considerar ambas lecturas como igualmente auténticas y justificarlas ambas; pues nada nos asegura, en efecto, que tales variantes no circulasen ya en los originales griegos y, como antes dije, que los códices medievales, y hasta los propios escoliastas, no hayan tenido acceso a textos de suyo diferenciados, responsables de la fragmentariedad de la tradición manuscrita. Con esto vuelvo a repetir que la pretensión de llegar a la reconstrucción de un arquetipo único es, además de imposible, seguramente no más que una ficción imaginaria. Pero lo que resulta de ello no me parece especialmente preocupante. Pues nada hay que temer de un cierto pluralismo, 
en todo caso muy concreto y poco numeroso, de nuestras lecciones, que, como demuestra el texto que acabo de comentar, enriquece más que perturba nuestra comprensión de ARISTÓteles.

\section{III}

Hasta aquí, pues, los criterios y decisiones de crítica textual sobre los que se ha basado mi edición. Pasaré ahora a informar brevemente sobre los problemas que antes he llamado de análisis histórico. En este punto, además de una actualización de fuentes conforme a las ediciones que han ido apareciendo a lo largo de nuestro siglo, mi edición rectifica o matiza en no pocos detalles las hipótesis de SPENGEL y COPE a propósito de concretas referencias históricas o literarias que aparecen en la Retórica. Conviene advertir que estas rectificaciones son importantes, a veces, para la comprensión del texto y no sólo para la autosatisfacción erudita, pero también, en todo caso, que constituyen minucias de índole menor, en modo alguno adecuadas para que yo las exponga aquí. En cambio, cuando hablamos de cuestiones históricas, hay un problema que se alza gravemente como un obstáculo en nuestro camino, sin vencer el cual, como ahora mostraré, difícilmente se puede avanzar en una real ponderación de esta obra de ARISTÓTELES. Me refiero al problema de la composición de la Retórica y a las dificultades introducidas por la aplicación de los métodos genéticos en el horizonte de la interpretación global del Estagirita.

Con referencia a la Retórica, la prehistoria del problema es larga y compleja. Ya BRANDIS (en su «Über Aristoteles Rhetorik- und die griechischen Ausleger derselben», de 1849) sostuvo que la Retórica era una obra mal estructurada, tal vez una primera versión con muchas correcciones posteriores, que ARISTÓTELES no habría tenido la oportunidad de corregir personalmente. En esta interpretación la responsabilidad se hacía recaer sobre el propio ARISTÓTELES; pero el modelo más común de explicación fue el de suponer interpolaciones para cada una de las incongruencias del texto, tarea esta que emprendieron sistemáticamente, tanto L. SPENGEL (en su Über die Rhet. des Aristoteles, de 1851, y más aún en su edición con comentarios, publicada en Leipzig en 1867), como J. VAHLEN (en su «Zur Kritik der arist. Poetik und Rhetorik», de 1862). De la suma de estos análisis se desprendieron, como era natural, visiones de conjunto dominadas por el punto de vista de la fragmentación. NiEHBUR, por ejemplo, aventuró que la Retórica respondía a una obra juvenil de ARISTÓTELES, profundamente alterada y aumentada en la praxis escolar del Perípato. Y aun cuando CopE rechazó este diagnóstico, basándose en análisis de crítica filosófica que permitían deshacer muchas de las presuntas contradicciones, no por ello dejó de señalar cómo algunas dificultades e incumplimientos textuales debían resolverse mediante la apelación a reelaboraciones posteriores. Análogos motivos llevaron a ZELLER a suponer que en realidad la Retórica no fue (según su expresión) "publicada" nunca y que, puesto que contiene referencias a la Política una obra comúnmente tenida por incompleta a la muerte de ARISTÓTELES, su forma actual sólo podía responder a un proceso de revisión y acumulación de nuevos materiales, que habrían llevado a cabo los discípulos. Sobre la base de una recensión más rigurosa de las anotaciones de SPENGEL y VAHLEN, así como de sus propias investigaciones textuales a que ya me he referido aquí, ROEMER enunció, en cambio, en el Prólogo de su edición de TEuBNER, la hipótesis en cierto 
modo revolucionaria de que el texto transmitido de la Retórica podía muy bien ser una colación de dos versiones del original, una extensa y otra resumida, que hubieran sido mezcladas por un anónimo editor anterior a ANDRÓNICO. Y Fr. MARX, sensible a esta tesis, pero fijando más su atención en análisis de fondo, supuso (en su Arist. Rhetorik, de 1900) que nuestra obra era el producto de un redactor tardío, que habría unificado y desarrollado manuscritos escolares de tres cursos de ARISTÓTELES sobre retórica.

Como se ve por estas rápidas indicaciones aquí referidas exclusivamente al texto de la Retórica, pero análogas a las que podrían citarse en relación con otras obras aristotélicas, el clima que había de dar lugar a los métodos genéticos de JAEGER estaba ya firmemente establecido, por obra sobre todo de la filología alemana, en los comienzos del siglo XX. Y fue precisamente en Göttingen, en la tesis doctoral que presentó KANTELHARDT en 1911 con el título De Aristotelis Rhetoricis, donde por primera vez se hizo uso, antes de que JAEGER publicase sus célebres trabajos, de una metodología sensu stricto genética aplicada a la Retórica, según la cual las dificultades de esta obra podían resolverse mediante la introducción de un eje diacrónico de análisis y el subsiguiente aislamiento de fragmentos textuales cronológicamente diversificados. Siguiendo, pues, este método, KANTELHARDT razonó que la Retórica ganaba en coherencia y unidad, si se suponía que el cap. I, 1 (concretamente desde 1354a11, con exclusión del párrafo preliminar de las líneas 1354a1-10) era anterior al resto de la obra, lo que, sobre ofrecer un marco explicativo a los análisis textuales de ROEMER y MARX, podía fundamentarse en la distinta elaboración que ARISTÓTELES lleva a cabo respecto de las "clases de pruebas", las cuales, en efecto, se reducen en I, 1 exclusivamente al entbyméma, mientras que se amplían en I, 2 al tekmérion y al parádeigma.

Ahora bien, en estas mismas coordenadas de análisis, pero por aplicación ya de los puntos de vista de JAEGER y en el marco de una reconstrucción general del Organon aristotélico, Fr. SOLMSEN, discípulo de aquél, sostuvo que en la Retórica que hemos conservado podían aislarse dos redacciones principales, correlativas a dos técnicas de argumentación, una según el modelo de los "lugares comunes" (ek tópon), y otra según el modelo de los "enunciados" (ek protáseon), redacciones que, aun si posteriormente mezcladas, procedían en realidad de dos épocas distintas de la investigación de ARISTÓTELES: las de los periodos docentes de la Academia y el Liceo. Y aunque desde posturas críticas, este mismo punto de vista se ha prolongado después en K. BARWICK, para quien la Retórica es «un manuscrito escolar, a cuya redacción ha añadido posteriormente Aristóteles una serie de suplementos»; y en P. GOHLKE, quien (en medio de un complejo análisis, que pone en el paso de la metodología típica a la analítico-silogística el principio fundamental de la reconstrucción del Organon) entiende que el texto transmitido de la Retórica se compone de una primera redacción, posterior a Tópicos, pero anterior a una versión inicial, hoy perdida, de los Analíticos y una segunda redacción, posterior a esos Analíticos perdidos, pero anterior a los que conservamos, cuya génesis podemos de este modo establecer.

Respecto de estas lecturas genéticas de la Retórica, y en general del entero Corpus de ARISTÓTELES, hay que decir, desde luego, y de la manera más enérgica, que la bibliografía actual se halla en un nivel de franca superación. Más aún: tal superación se daba ya como un hecho irreversible y así sigue en la generalidad de los estudios de hace 20 años sobre el estatus de la investigación aristotélica, como puede constatarse en los 
trabajos de E. BERTI, Aristotele nella critica e negli studi contemporanei (Milán, 1957), o en el algo más reciente de A. H. CHROusT, Die ersten dreissig Jabre moderner Aristotelesforschung (Darmstadt, 1968). Por una parte, los resultados de las reconstrucciones genéticas no han sido mutuamente concordantes e incluso, como es el caso de I. DüRING, al que me referiré luego, han sido discutidas en sus mismas bases filológicas. Y, por otra parte, y sobre todo, tales reconstrucciones subvierten lo que no es más que la aplicación de un método histórico, al presentar a éste como si se tratase de una tesis de interpretación filosófica. Ahora bien, visto así el problema y, por decirlo con las palabras de P. AUBENQue, lo único que consiguen es sustituir «la comprensión horizontal, que multiplica las conexiones del sistema (...) por las diferentes etapas de un problema o de una noción» (La prudence chez Aristote, Paris, 1962, p. 26). El resultado es un predominio de lo discontinuo y el fragmento, en donde la coherencia del filósofo es sacrificada a la metodología del intérprete o, dicho de otra manera, en donde la lectura sintética de las obras es preterida en favor de una lectura analítica de sus conflictos; y ello en una forma en la que ARISTÓTELES queda completamente desarticulado, de suerte que sólo cabe ya al modo como lo intentó JAEGER una interpretación global de su pensamiento en tanto que referido al curso íntegro de su biografía. Es muy dudoso, ciertamente, que este modo de proceder pueda presentarse como un principio hermenéutico legítimo. Pero, sobre todo, lo que hay que decir es que con su aplicación no se gana en realidad nada respecto del estado de cosas resultante de los estudios del siglo XIX: en ambos casos, en efecto, y lo mismo si se utilizan perspectivas sincrónicas que diacrónicas de análisis, lo que el intérprete debe preguntarse es si resulta plausible que ARISTÓTELES pasase de una tesis a otra distinta, sin reparar en las consecuencias que su mera fusión podía tener para el conjunto de cada obra, o si más bien las presuntas contradicciones pueden ser disueltas mediante exámenes o hipótesis de orden general que las justifiquen. Este último punto de vista, que, por lo que atañe a la Retórica, no hace más que seguir el criterio ya formulado en los años treinta por H. THROM, es seguido ahora por W. H. GRIMALDI (que polemiza abiertamente con los métodos genéticos) y por J. SPRUTE (que tiene, en cambio, tales métodos por irrelevantes).

Así pues, la superación de las interpretaciones genéticas configura hay que insistir en ello el clima de las actuales investigaciones sobre la Retórica. Sin embargo, si con esto resulta claro que la interpretación ha de situarse en las coordenadas de una explicación unitaria y suficientemente comprehensiva del pensamiento de ARISTÓTELES, con todo, sería absurdo suponer que la aplicación de tal criterio metodológico suprime los problemas que plantea la composición de sus obras. En el caso que nos ocupa, las evidencias sobre tensiones conceptuales, reajustes y desarrollos diacrónicos son demasiado fuertes como para no pensar que la Retórica ha tenido una gestación morosa y acumulativa, en un transcurso de tiempo que además hemos de suponer dilatado. Ahora bien, si con la información de que disponemos no se alcanza, por lo tanto, a suspender esta mayor verosimilitud de las hipótesis diacrónicas, lo que en estos márgenes quiere decir la superación de los métodos genéticos es que, por primera vez, el análisis de los diferentes niveles de composición de las obras del filósofo puede afrontar una interpretación razonada de conjunto, sin desatender por ello la historia real de su pensamiento. Nada impide que ARISTÓTELES, a medida que haya ido corrigiendo y aumentando el cuerpo de sus lecciones, se haya guiado en todo instante por un criterio de integración sistemática; pero, más aún, lo que la aplicación de un eje diacró- 
nico permite establecer es eso precisamente: el esfuerzo de síntesis, tal como queda reflejado en los sucesivos episodios de la escritura de sus obras. A partir de ahí, la tarea del investigador no es ya o no de un modo predominante la de preguntarse qué tensiones o qué estratos cronológicamente diferenciados se pueden reconocer en los escritos de ARISTÓTELES, sino en virtud de qué criterios ha tenido él tales estratos y tensiones como conciliables sistemáticamente, hasta elaborar con ellos un único producto intelectual. Y éste es el núcleo de la cuestión.

A la luz de este planteamiento, los problemas que formula la composición de la Retórica pierden en gran medida su configuración polémica. Para tales problemas, en efecto, las virtualidades de los análisis sistemáticos, al modo de los que practica GRIMALDI, son perfectamente legítimos, puesto que remiten a una obra única y completa; pero también escasamente decisorios, ya que ponen como punto de partida lo que en realidad es el punto de llegada, o sea, la propia síntesis o unidad intelectual sin duda querida por ARISTÓTELES que representa el libro. Y en cuanto a los análisis filológicos, tales como los que ha llevado a cabo DüRING, hay que decir en rigor que resultan poco consistentes. DüRING no ha logrado mantener, después de todo, su tesis de la unidad textual de la Retórica. Su afirmación de que los cap. II, 23-24 constituyen un añadido al cuerpo de los libros I-II viene a mostrar que la obra ha experimentado rectificaciones respecto de su redacción original. Pero lo mismo cabe decir de la cita de Diópites (II, 8, 1386a14), al que DüRING identifica con el general citado por DEMÓSTENES en Corona $\$ 70$ y que, al situar este pasaje en una fecha no anterior a 310, tiene que explicar como «una revisión particular (...) en medio de una abigarrada serie de ejemplos» (cfr. Aristoteles, Heidelberg, 1966, p. 120). O también de la anécdota de «uno que dio una estera en el Liceo» (II, 7, 1385a18), que DüRING, en cambio, calla y que no puede sino presuponer la segunda estancia ateniense de ARISTÓTEles. Desde luego, si éste impartió docencia de retórica en el Liceo, como confirman otras fuentes paralelas, es completamente inverosímil, considerando las nuevas conquistas realizadas por él, sobre todo en el terreno de la lógica, que hubiera querido servirse, sin grandes modificaciones, de un texto tan antiguo como un tratado académico sobre la argumentación retórica. Y a esto debe añadirse todavía que las razones sobre las que DüRING justifica su punto de vista son muy poco convincentes. Su argumentación principal sobre que en la Retórica no se hallan alusiones a los discursos de DemóstenEs por lo que, como la carrera del afamado orador no comenzó hasta el 354, la composición de la obra debe ser en conjunto anterior a esa fecha, constituye un razonamiento demasiado débil, si se atiende a la militancia política de DEMÓSTENES y a la posición en que se encontraría ARISTÓTELES como antiguo preceptor de Alejandro en una Atenas dominada por la pasión antimacedonia: elementales razones de prudencia pueden explicar el que ARISTÓTELES evitase cualquier mención de DEMÓSTENES, susceptible, como ya había ocurrido veinte años antes con IsÓCRATES, de acarrear disputas, también en el caso de que algunas partes de los libros I-II de la Retórica hubiesen sido redactados tardíamente. Fuera de esta argumentación, DüRING practica sobre las dificultades y desajustes de la obra un espeso silencio. Y tampoco se pronuncia sobre el esencial problema del doble código metodológico de la Retórica: su afirmación de que ARISTÓTELES había ya escrito en el periodo académico la casi totalidad de los Tópicos y algunas partes de los Analíticos, como no se refiere en concreto a ninguno de los pasajes objeto de discusión, resulta tan general como indecidible. 
Ahora bien, este último punto es el fundamental. Ciertamente, los motivos para una distinción diacrónica de constructos temáticos en el interior de la Retórica vienen dados por la existencia de una doble organización de la «lógica de la argumentación persuasiva», que presupone, en cada caso, el modelo de Tópicos o de Analíticos y cuyos paradigmas se ofrecen respectivamente en los caps. 1 y 2 del libro I. Sobre las notorias heterogeneidades de estos dos capítulos no cabe aceptar el fácil argumento, que propone DufOuR, de que ARISTÓTELES podría estar hablando en I, 1 de una forma meramente programática frente a la más detallada exposición de I, 2. Tal tesis es, desde luego, muy poco sólida, aparte de porque esas mismas heterogeneidades se prolongan después, de un modo bien tangible, a lo largo de la obra, por un dato más concreto que, hasta donde yo conozco, ha sido poco tenido en cuenta; a saber, porque, incluso si admitimos que I, 1 tiene el carácter de un programa aún sin precisar, el modelo lógico-retórico que formula coincide estrictamente con el, esta vez sí, preciso y muy desarrollado de III, 17 (donde ARISTÓTELES, al hilo de la construcción o táxis de los discursos, repite sus consideraciones sobre la argumentación retórica), en un sentido que no ya sólo tiene poco que ver con lo que leemos en I, 2, sino que, más aún, discrepa seriamente de la doctrina que este último elabora a propósito del programa mismo del saber retórico.

En el primero de estos paradigmas, ARISTÓTELES concibe la retórica en el marco de la crítica al inmoralismo sofista y prohíbe, en consecuencia, el uso de todos los argumentos que se hacen «pros tón dikastén»: con vistas a convencer, de cualquier modo que sea, a quien ha de juzgar. Las argucias basadas en la exhibición por parte del orador de un talante moralmente bueno o la sustitución de los razonamientos por la excitación de las pasiones del auditorio son condenadas enérgicamente o, a lo sumo, sólo admitidas para hacer más digeribles ante auditorios incultos las argumentaciones lógicas. Toda la persuasión ha de fundarse, pues, según este modelo, en la presentación de los «hechos» (prágma) y en el uso de aquellos razonamientos (lógoi) que pueden obtenerse a partir de enunciados o inferencias generales que, por su parte (y luego me extenderé sobre este punto), derivan de tópoi o lugares comunes de naturaleza dialéctica. La proximidad de este planteamiento a tesis platónicas bien precisas y su conexión con temas que ARISTÓTELES desarrolla en Tópicos permite asegurar que todas las partes o secciones de la Retórica en que tal modelo es reconocible pertenecen a una redacción temprana, que seguramente se ha de relacionar con el célebre y enigmático Curso de retórica del periodo académico del que nos informan los índices antiguos de las obras aristotélicas.

Por su parte, el segundo modelo presenta una situación en la que las exigencias morales han sido depuestas en favor del análisis minucioso de las técnicas de la persuasión. El problema es ahora más propiamente el de la modificación de las conductas, lo cual implica un más detallado examen de los elementos emocionales de la persuasión. Los enunciados que connotan tales elementos, o sea, los que expresan los caracteres y las pasiones, son considerados ahora por ARISTÓTELES como susceptibles de proporcionar premisas al razonamiento, en el mismo plano que los que se refieren al prágma o asunto de los discursos. Esto obliga a sustituir la concepción original respecto de la necesidad de valerse exclusivamente de enunciados generales y, a la inversa, introduce en la retórica abundantes catálogos de enunciados particulares (ídiai protáseis), susceptibles de enseñanza, de los que el orador puede hacer uso, con sólo recor- 
darlos, bajo cualesquiera circunstancia como materia de sus argumentaciones. Esto quiere decir que ARISTÓTELES concibe tales enunciados particulares ellos mismos como lugares comunes, por lo que no siente que haya ninguna contradicción entre el primero y el segundo de sus planteamientos y puede sobreponerlos meramente: con ambas técnicas, en efecto, no hace sino proporcionar términos medios a los razonamientos de que haya de usar el retórico. Pero la disposición de esos catálogos de enunciados le permite, en cambio, reorganizar la retórica conforme a los cánones de toda argumentación, es decir, le permite construir inducciones y silogismos específicamente retóricos, lo que implica una reordenación de los argumentos persuasivos según el modelo de los Analíticos.

Si las hipótesis que he manejado en mi edición son ciertas, esta reordenación final de la Retórica debió tener lugar a principios del periodo del Liceo, más o menos entre 335 y 330 . Pero lo importante es hacer notar cómo a lo largo de una composición que los dos estratos principales nos muestran tan dilatada, ARISTÓTELES ha juzgado siempre tener entre manos un mismo proyecto, bien fundido y coherente. La pregunta que se plantea es si podemos descubrir el sentido, el valor íntimo - y, en todo caso, unode este proyecto. Pero tal problema nos lleva ya a las cuestiones que antes he llamado de análisis filosófico, a las que, con toda rapidez, voy a dirigir ahora la atención.

\section{IV}

A propósito de éstas, de las cuestiones de análisis filosófico, a las que mi edición ha dedicado el interés prioritario, lo primero que hay que decir, de todos modos, es que formulan un interrogante, cuya falta de claridad no puede menos que producir asombro. Cuando se habla de retórica, resulta inevitable, en efecto, traer a la conciencia la imagen de un arte o una técnica de hacer discursos o más simplemente de hablar bien, en forma que tiene que ver con una suerte de preceptiva literaria, pero no con la verdad de lo dicho o con las decisiones del juicio práctico.

Esta imagen procede de la propia historia del Perípato, seguramente (si hemos de creer a Diógenes Laercio) a partir de la rectoría de Licón, y se consagra en la organización del Corpus de Andrónico de Rodas, que desgaja a la Retórica del Organon para unirla a la Poética. Cierto que el recuerdo de una retórica vinculada a la lógica de las decisiones prácticas se ha conservado en testimonios muy antiguos, así de las tradiciones estoicas, que en este punto tienen su origen en ARISTÓTELES, como del propio Liceo, según muestra la cita de QuiNTILIANO que se refiere a ARISTÓN, el predecesor de Critolao al frente del Perípato, y que define a la Retórica como «scientia videndi et agendi in quaestionibus civilibus». Cierto asimismo que en el arte del bien hablar nunca ha faltado un capítulo importante sobre la argumentación persuasiva y que una parte de la investigación contemporánea, desde SOLMSEN y GOHLKE, ha situado el libro de ARISTÓTELES entre los méthodoi o escritos de lógica. Con todo, a pesar de estas evidencias, y, más todavía, a pesar de que una línea importante de la reflexión contemporánea ha fijado sus ojos, a partir de PERELMAN, en las virtualidades de los modelos retóricos de argumentación como instrumentos de las decisiones éticas y políticas, la verdad es que la Retórica de ARISTÓTELES no ha logrado aún trascender los límites del interés por el Ars dicendi, en que la situaron las distintas tra- 
diciones escolásticas, ni integrarse, por tanto, en el universo de investigaciones que suscita desde siempre la filosofía práctica aristotélica. Un ejemplo de ello y un ejemplo que me parece sustantivo es que el gran debate sobre el modelo aristotélico de la racionalidad de la praxis, que enfrentó en Alemania, durante los años setenta y buena parte de los ochenta, a intelectuales tan solventes como GADAMER, HABERMAS,

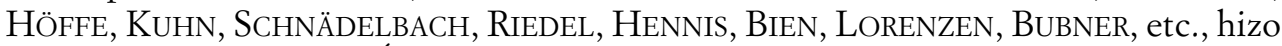
un uso constante de las Éticas, de la Política y de los Tópicos y, en cambio, apenas si tuvo en cuenta, y siempre además desde una perspectiva secundaria, los análisis de la Retórica. Ahora bien, ¿podría decirse que un tal planteamiento de la cuestión reproduce adecuadamente el punto de vista de ARISTÓTELES? ¿Ha de aceptarse que el sentido más profundo de la Retórica se agota en el Ars dicendi y que su valor es secundario en el orden de la filosofía práctica aristotélica? Ésta es la pregunta que, para explicar el objetivo último de mi edición, y ya en los breves minutos que me restan, quisiera ahora responder.

En rigor, para hacerse cargo de la posición de ARISTÓTELES hay que partir de las consideraciones platónicas en torno a la retórica y, simultaneamente, de las consecuencias que para el Estagirita tuvo la que C. VIANO ha llamado con acierto «crisis de la dialéctica». Los requisitos que con respecto a la retórica Platón había señalado en el Fedro se resumían en dos: ante todo, que sólo son verdaderos discursos los discursos que son verdaderos; y, después, que tal objetivo únicamente puede cumplirse cuando los discursos remiten a un plano adecuado de referencia ontológica, es decir, no a las opiniones o a las realidades sensibles, sino a las Ideas o Formas. Ahora bien, el cumplimiento de estos requisitos implicaba que todos los discursos dependiesen de un órganon o «discurso de los discursos», que pudiese establecer la conexión del lenguaje con los objetos esenciales comprendidos en él. Y tal órganon era la dialéctica, en cuanto que, mediante divisiones y composiciones de conceptos, permitía demostrar la validez de las definiciones y de los procesos deductivos empleados en los discursos. Desde este punto de vista, los únicos «discursos verdaderos» posibles eran los discursos científicos; y la retórica no podía ser entonces nada distinto de la dialéctica misma, puesto que, no siendo una ciencia particular y, al contrario, pretendiendo ella también ser un órganon o «discurso de todos los discursos», había de cumplir las mismas exigencias que la dialéctica y en nada podía diferenciarse de ésta.

Ofrece pocas dudas que, en el aspecto lógico del problema, ARISTÓTELES mantiene el marco íntegro de estas exigencias platónicas. Prescindiendo aquí de sus diálogos tempranos, cuya identificación con PLATÓN parece segura, lo cierto es que los libros VI-VII de Tópicos, que son, como se sabe, los más antiguos de esta obra, nos presentan también a la dialéctica como un arte para la demostración de las definiciones de que hacen uso las ciencias particulares. Es cierto, de todos modos, que ARISTÓTELES se separa de PLATÓN en un punto fundamental, en el que la «crisis de la dialéctica» aparece ya consumada; a saber, en que las cosas contingentes no pueden ser referidas adecuadamente (orthós) a la necesidad de las Ideas. Tópicos VI-VII presuponen ya, a este respecto, la crítica de las Ideas, que sin duda contenía el Perí tón idéon y que podemos reconstruir a través del libro A de Metafísica. Sin embargo, si esta renuncia equivale a una rebaja en las pretensiones de cientificidad de la dialéctica, todo el esfuerzo de ARISTÓTELES se dirige a reconstruir un horizonte de certi- 
dumbre (aunque sólo sea relativa) en el orden de la contingencia. No es posible avanzar, a mi juicio, en la comprensión del pensamiento aristotélico, sin percibir este punto de partida que lleva a ARISTÓTELES a salvar el platonismo contra el propio PLATÓN. La reconstrucción de algún orden de certeza para el mundo contingente implica, así, la transformación de la dialéctica en un sentido que pueda conservar el maximum posible de sus pretensiones epistemológicas, sin el apoyo de la referencia a las Ideas. Y ésta es la clave del problema que quiero presentar: tal transformación incluye, como un requisito suyo, no la suspensión de la retórica, sino, al contrario, su pleno desarrollo y constitución autónoma.

El razonamiento aristotélico podría sintetizarse del modo que sigue: si las Ideas no pueden servir de plano de referencia ontológico a los enunciados del lenguaje que remiten a objetos contingentes, en cambio, la pluralidad de sentidos que la contingencia introduce sí puede unificarse desde la identidad de la definición, que, de este modo, se perfila ahora como un nuevo criterio de significado. Lo que tal criterio postula es que «todo objeto ha de tener una única definición, que debe poder sustituir al nombre del objeto en todo contexto en el que aparezca» (VIANO, art. cit., p. 382). La demostración de las definiciones, en que se resume el objetivo de la dialéctica, consiste entonces, desde este punto de vista, en buscar todos los contextos en que puede aparecer el nombre del objeto, a fin de comparar en cada caso la identidad de su definición. Tales contextos funcionan, así pues, como «lugares (tópoi) lógicos» de la «demostración (syllogismós) de las definiciones». Y, por esta causa, el «método de selección (trópos tés eklogés) de estos lugares», en que se resume todo el programa demostrativo, recibe con plena justicia el nombre de Tópica.

En las coordenadas de este nuevo planteamiento, la división y jerarquía de los conocimientos humanos halla un sencillo marco de explicación. Las ciencias particulares se presentan, en efecto, como discursos que de antemano han cumplido ya las exigencias de la dialéctica, sencillamente porque se refieren a casos saturados en que la contradicción es imposible o, dicho de otra manera, en que la identidad de la definición es puesta como principio en todos los contextos o lugares lógicos en que puede aparecer; y es en este uso de las definiciones como principios en lo que consiste la axiomatización de las ciencias. En cambio, los enunciados para los que sí cabe la contradicción de lo que afirman, sin que pueda presuponerse de antemano la identidad de su definición, tienen que probar ésta, consecuentemente, recorriendo todos los lugares lógicos. Son tales casos los que pertenecen ahora al dominio propio de la dialéctica: sus definiciones no pueden proponerse como principios, sino como bipótesis. Y la dialéctica se constituye entonces como un método para la selección y justificación de hipótesis.

Ahora bien, con esto llegamos al centro del asunto. A las hipótesis no les corresponde un plano de referencia necesario como si ya fueran verdades; les corresponde únicamente el estatuto de dóxai, de opiniones. Una tesis que puede ser sometida a contradicción, es decir, de la que no se sabe todavía si se cumple en todos los contextos posibles, constituye una opinión, un enunciado de validez subjetiva; y la «posibilidad de contradicción» sólo puede ser interpretada entonces, según lo dice Tóp. VIII, 1, 155b 3, como «posibilidad de confrontación con otras opiniones», o sea, como diálogo o controversia con un oponente. Es bastante obvio que, al plantear así el problema, la referencia de las proposiciones cambia de dirección: ya no remite a un plano 
real, óntico, que lleve a las cosas o a las Ideas, sino a un plano lingüístico, a un plano de creencias sociales en las que el significado de la definición se produce siempre en el orden de lo que se dice. Sin embargo, ARISTÓTELES cree poder conservar todavía algún tipo de criterio semántico, puesto que, a su vez, el cuerpo de creencias sociales refiere mediatamente al orden de la realidad sobre el que aquellas creencias se sostienen. De ahí que las opiniones que «comparten todos o, al menos, la mayoría o, si no, los más sabios» (Tóp., I, 10, 104a8) resulten ser más dignas de crédito que sus contrarias, por cuanto su mayor o más cualificada aceptación es signo de una mayor integración en el sentido de la unidad de su significado. Las opiniones más plausibles, más sujetas al acuerdo social, son, desde este punto de vista, también las más probables ontológicamente. Y, de este modo, la dialéctica puede superar el mero arte de la controversia entre pareceres (en que se halla instalada la erística) para situarse en el marco de un cálculo de probabilidades, susceptible de asignar a cada proposición la cuota de verdad que le corresponde.

ARISTÓTELES piensa, ciertamente, que la misión de la dialéctica queda ahora perfectamente establecida. Por una parte, las creencias sociales forman, a su modo, un sistema, una trama organizada de enunciados, que duplica, mencionándolo mediatamente, el sistema de la realidad: ellas operan, pues, aun si en el nivel lingüístico que les es propio, como experiencia, como criterio material de verificación. Pero entonces, por otra parte, la dialéctica puede probar la mayor credibilidad de una tesis por el procedimiento de confrontarla con el sistema de opiniones comunes, lo que en definitiva quiere decir, por la constatación de la identidad de sus usos en el contexto de los lugares lógicos de la opinión común. Bajo estas condiciones, a la dialéctica le cabe operar, en fin, al modo como operan las ciencias; esto es, partiendo de lo que es más o menos objeto de opinión común y obteniendo a partir de ello premisas verosímiles que pueden formar parte de razonamientos análogos a los razonamientos científicos. Pero si, de este modo, la dialéctica se orienta ya de una forma definitiva en una orientación que va de las opiniones a las cosas de lo plausible a lo probable, salvando así, hasta donde es posible, el ideal platónico fuerte de la referencia a la verdad, es precisamente en este punto donde un completo desarrollo del programa dialéctico obliga a que éste se divida en dos disciplinas complementarias.

Porque, en efecto, la "probabilidad" no transforma, de todos modos, en casos saturados (científicos) las proposiciones del dialéctico ni remonta tampoco el carácter en todo caso lingüístico de la referencia: no hay en ARISTÓTELES — he aquí el núcleo del asunto- una teoría de la probabilidad al margen de la dóxa. Pero, por ello mismo, la dirección que va de las opiniones a las cosas tiene que ser complementada con la dirección que va del dialéctico a su oponente. Como la mayor credibilidad de una tesis no impide la posibilidad de su contradicción, el problema de determinar mediante razonamientos dialécticos que ella es más probablemente verdadera halla su réplica en el problema de persuadir al oponente mediante argumentos de convicción objetivados en el discurso. O dicho de otro modo: supuesta la no necesidad absoluta de las tesis del dialéctico, al análisis de las condiciones que hacen posible su verificación relativa (su mayor cuota de verdad, en el sentido platónico del criterio de la referencia) debe seguir el análisis de las condiciones que hace posible su comunicación. Pues bien, este último análisis es el que desarrolla la retórica. 
Así pues, la dialéctica se fija en los enunciados probables desde el punto de vista de la función designativa del lenguaje, de lo que resultan conclusiones sobre la verosimilitud de tales enunciados; la retórica centra su interés en esos mismos enunciados desde el punto de vista de las competencias comunicativas del lenguaje, de lo que se desprenden ahora conclusiones sobre su capacidad de persuasión. Esta duplicidad de problemas que afronta la cuestión de los conocimientos probables y que reproduce casi exactamente, como lo indica APEL, «la distinción entre las dimensiones semántica y pragmática en el moderno análisis del lenguaje», localiza la perspectiva fundamental, desde la que se hace comprensible el sentido del programa aristotélico en torno a la retórica.

De una parte, no se trata de hablar bien o de construir discursos elegantes, sino de hacer posible una comunicación transparente y controlada. De otra parte, no se trata tampoco de convencer a cualquier precio de no importa qué materias (que sospechosamente, como ya lo había denunciado Platón en el Gorgias, coinciden siempre con aquellas que son de interés de quien detenta el poder o a él aspira), sino de convencer de lo que tiene a su favor la mayor probabilidad de ser verdadero. Este programa, que hace de la retórica un instrumento de la «prudencia ética y política», encuentra finalmente su auténtica justificación sobre la base de la complementariedad por primera vez definida en sentido riguroso, por más que olvidada en el desarrollo de las tradiciones escolares de las funciones del lenguaje, sólo en cuyo universo, en ausencia de una completa absorción científica de la praxis, resulta pensable una racionalización de la acción humana. ARISTÓTELES sabe muy bien que ese «universo del lenguaje» constituye y delimita en su integridad el entero «mundo del hombre». Y, por eso, las palabras inaugurales de la Retórica, esas que por ser las primeras siempre se hallan revestidas de la solemnidad que les da su posición privilegiada, las dedica ARISTÓTELES a afirmar que «la retórica es una antistrofa de la dialéctica». Una antistrofa: o sea, la réplica con que una parte del coro trágico contestaba a la estrofa entonada por la otra parte y cuya estructura poética paralela, así como la identidad conversa de sus pasos de danza, daban la medida de la unidad del canto. Para esta unidad, en la que se coimplican y se copertenecen las funciones semánticas y pragmáticas del lenguaje, el paso de los razonamientos según lugares comunes generales a inducciones y silogismos de probabilidad debe ser interpretado como el perfeccionamiento sucesivo (en la intención de ARISTÓTELES) de un proyecto común de absorción de la contingencia y de la praxis en esquemas racionales de alguna solidez. No es que esta absorción garantice, entiéndase bien, que los juicios y proposiciones resultantes puedan ser confirmados por una verdad capaz de absorber la diferencia de opiniones. Lo que garantiza es unas reglas claras de juego tanto en las argumentaciones positivas como en el diagnóstico de los paralogismos, donde la confrontación pragmática de los pareceres, en el seno de un diálogo con voluntad de realizarse en la esfera pública y, por tanto, ante la atenta circunspección de los oyentes, necesariamente ha de verse abocada a mantener una apuesta por la verdad más plausible, entendida, como mínimo, en el sentido de aquella que ofrece más restricciones y obstáculos a la expansión de la irracionalidad. Y éste es, a mi juicio, el fondo de lo que se propone en el programa aristotélico de la Retórica. 
Lo que se propone en el programa aristotélico y quizás también habría que añadir, al menos como un desideratum lo que debería proponerse en aquellos programas filosóficos contemporáneos que buscan ampliar la imagen de la racionalidad basándola en modelos argumentales. Porque, ciertamente, en las coordenadas que estos modelos diseñan, y estoy pensando tanto en los cognitivos, al modo del de SPERBER y WILSON, como en los estructuralistas de ANSCOMBRE y DuCROT; y asimismo, tanto en los estrictamente pragmáticos, a la manera de los de HABERMAS o ALEXY, como en el más analítico de MACCORMIC, en todos estos modelos, digo, tal vez no resultaría inadecuado subrayar de un modo más enérgico los dos postulados que, en definitiva, subyacen a la metáfora de la antistrofa entre la dialéctica y la retórica. A saber: el primero, que la ausencia de fundamentos legitimadores (en sentido fuerte) de las decisiones éticas y políticas no debe impedir el proyecto de una racionalización de las relaciones humanas, que sólo cabe esperar de una decidida apuesta a favor de la transparencia comunicativa del lenguaje frente a las implicaciones siempre oscuramente interesadas de los discursos confusos. Y el segundo, inverso del anterior, que el intento de una reestructuración del sentido de las proposiciones exclusivamente basada en la arquitectura de una pragmática universal, no puede perder de vista que, de cualquier modo, todo proyecto de racionalización pasa por no renunciar al control de las meras competencias comunicativas bajo el imperio de una fundamentación progresiva (basta donde en cada momento resulte posible) de la verdad. Estos dos postulados atraviesan, sin duda, una buena parte de la filosofía actual. Y lo que creo es que a ninguno de los dos puede serle ajena la tarea de repensar la retórica. 